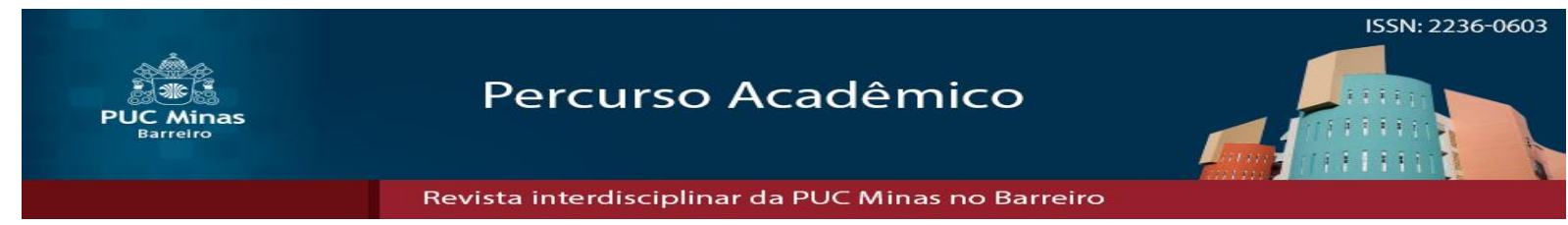

\title{
Economia e (direito do) trabalho em um contexto de quarta revolução industrial: uma análise crítica da lei 13.467/17.
}

\section{Economy and (labor law) in a context of the fourth industrial revolution: a critical analysis of the law 13.467 / 17.}

\author{
Vicente de Paulo Alves de Oliveira ${ }^{1}$ \\ Ugo Briaca de Oliveira $^{2}$
}

\section{Resumo}

O mundo está em constante mudança. Contemplando o cenário histórico da Revolução Industrial que alcança sua quarta versão, torna-se oportuno um estudo acerca de suas consequências práticas para os aparatos sociais voltados à economia, ao gerenciamento, à produção e ao trabalho. Para tanto, é necessário entender o caráter altamente correlacionado destes agentes, os quais funcionam de forma proporcionalmente interligada. Tendo em vista este cenário, urge avançar para a construção de uma análise crítica acerca da reforma trabalhista (Lei 13.467/13), visando então compreender quais são os seus propósitos e, sobretudo, se estes se sustentam em um ambiente de macroeconomia, a médio-longo prazo, num contexto de quarta Revolução Industrial. Assim, buscar uma conclusão pela aplicação da Lei 13.467/13 no âmbito prático, e se esta, de fato, poderá promover o setor produtivo, atrelada às promessas de criação de novos postos de trabalho, por meio de sua implementação, é essencial para o cumprimento dos objetivos socioeconômicos pretendidos.

Palavras-Chave: Quarta Revolução Industrial, Globalização, Economia, Reforma Trabalhista.

\begin{abstract}
The world is constantly changing. Contemplating the historical scenario of an Industrial Revolution, arrived on its fourth version, became in an opportunity to make a study regarding its practical consequences for the social facilities system, geared to economy, management, production and labor. Therefore, it is necessary to understand the high correlation among these agents, which work proportionally integrated. In view of this scenario, it is urgent to move towards the construction of a critical analysis about the labor reform, inaugurated by the Law $13.467 / 13$, in order to understand what are its purposes and, specially, if it is based in a macroeconomic environment, in a medium and long term, and in a context of the fourth Industrial Revolution. Thus, seeking a conclusion by the application of the Law 13467/13 in a practical scope, and if this in fact can promote the productive sector, tied to the promises of creating new jobs through its implementation, is essential for meeting the intended socioeconomic objectives.
\end{abstract}

Keywords: Fourth Industrial Revolution, Globalization, Economy, Labor Reform.

Artigo recebido em 15 de abril de 2018 e aprovado em 24 de setembro de 2019

${ }^{1}$ Professor na Graduação: PUC - Minas (2002 - 2018); na Pós-Graduação: Centro Universitário UNA (2006 2013), Fundação Dom Cabral (2004 - 2008), Faculdade SENAC Minas (2005 - 2007). Fiat Automóveis S.A.: 1976 - 2015 (Áreas Administrativa, Comercial e Logística). Cia. Souza Cruz Ind. e Com. (1971 - 1976). Orientador. Mestre em Engenharia da Produção pela Universidade Federal de Santa Catarina. E-mail: oliveira.vicente@uol.com.br.

${ }^{2}$ Mestre em Direito Privado, linha de pesquisa Direito do Trabalho, Modernidade e Democracia, pela PUC/MINAS. Especialista em Direito e Processo do Trabalho pela PUC - Minas. Advogado e consultor jurídico. E-mail: ugo_23@hotmail.com 


\section{Introdução}

O mundo mudou e o faz continuamente. Em decorrência das transformações, vivenciou nos últimos séculos, e em especial no século $\mathrm{XX}$, uma inumerável sequência de inovações de todos os gêneros, na indústria, na política e na economia. Estes elementos construíram um ambiente para o século XXI, cuja dinâmica alterou de forma profunda e permanente as relações sociais. Para Standing (2013, p. 23), ao deixar de lado, já em um primeiro momento, as sociedades agrárias, "a era da globalização resultou numa fragmentação das estruturas de classe nacionais", e isto, em contextos diversos, como aborda o mesmo autor. E argumenta Hobsbawm (2002, p. 283) que, por conta "de constante mudança, transformação tecnológica e inovação cultural [...] para a maior parte do globo as mudanças foram igualmente súbitas e sísmicas".

Aquilo que para muitos estudiosos, entre eles José Ortega y Gasset, representaria uma versão distópica da sociedade - um futuro imerso na barbárie, no retrocesso e na decadência - acabou por se revelar em um arranjo de construção dinâmica, confirmando por verdadeira a profunda correlação entre a histórica tríade economia, trabalho e consumo.

Completa a referida tríade de fluxos, claro, o sistema produtivo, que ao seu turno teve uma evolução conturbada e frenética entre os séculos XVIII e XXI.

A partir de uma revolução industrial que introduziu o valor de extração do trabalho desumano em privilégio do franco avanço fabril, até experiências acerca de modelos de produção e ganhos atrelados a condições cada vez mais dignas de trabalho, é certo que a caminhada das ciências econômicas e gerenciais teve de, necessariamente, passar pelo boom dos séculos anteriores, para chegar plena na atualidade, reinventando, com cada vez mais dinamismo, os modos de se materializar a economia.

Nota-se, portanto, sucessivas variações de modelos de gestão, como o sistema de produção enxuta (também referido como o sistema Toyota de produção), os quais, pouco a pouco, foram agregando-se em formas cada vez mais criativas, produtivas e disruptivas que, literalmente, trouxeram uma realidade inteiramente nova e inovadora, conforme Ohno (1997) e Shimokawa \& Fujimoto (2011).

O legado da história econômica estimula um recorte sobre como a economia, catalisada pelas cadeias de produção, conflui sintomaticamente no trabalho, que, para o 
presente ensaio. foi analisado em suas mais diversas formas, notadamente sob os aspectos legislativo e econômico/gerencial.

Nesse sentido, não há como fugir do princípio de que a economia está conectada ao próprio (direito do) trabalho e, com efeito, ambos são alterados ao sutil toque das formas de produção e estratificação do labor humano.

Acerca destas últimas, dentre tantos modelos que a cada dia surgem, é indene de dúvidas serem autênticos modos geradores da automatização, e se valem desta para um desenvolvimento mais rápido e crescimento do lucro do setor produtivo. Se reinventam de tempos em tempos, para não permitir que o aparato econômico fique estagnado: o mercado se adapta, mas para tanto, não lança mão somente da economia.

Ademais, se a economia é um fenômeno heterodoxo, polivalente e metamórfico, altamente adaptável às mais diversas alterações causadas pela confluência entre os mais diversos fluxos (consumo, política, sociedade...), por certo o (direito do) trabalho também o é.

O presente estudo centra-se no percurso histórico da economia e eventuais evoluções de modelos gerenciais, sua entrada no século XXI e sua correlação com o (direito do) trabalho. Visa identificar se as relações de trabalho e o modelo econômico, atrelados à cadeia de produção, irão permanecer conforme foram entendidos até o momento e onde entraria o direito do trabalho enquanto mediador nessa relação. Perceba-se, a economia evolui, na mesma proporção em que a cadeia de produção evolui. Paralelo a isto, existe o instituto do direito do trabalho, cuja história é, ao mesmo tempo, paralela e entrelaçada a estes.

Portanto, enquanto direito regulador do trabalho, em que pese a reforma promovida pela Lei 13.467/17, que altera a Consolidação das Leis do Trabalho (CLT), a fim de adequar a legislação às novas relações de trabalho, o direito obreiro consente ou reprova o cenário econômico atual?

Visto até sob uma perspectiva global, o cotejo economia e direito do trabalho evoluem com as reformas legislativas promulgadas em período recente no Brasil?

Portanto, torna-se importante investigar essa correlação, buscando identificar as perspectivas, seja para a área das ciências econômico/gerenciais, assim como para a jurídica, acerca da nova configuração de que se reveste o século XXI.

A partir destas considerações, este artigo tem por objetivo colocar em evidência alguns dos aspectos mais contemporâneos dos impactos verificados no mundo do trabalho, que sempre esteve, e assim continuará, em permanente mutação. Usar o termo mutação em substituição à evolução poderá ser útil, uma vez que o resultado não necessariamente conduz 
a uma mínima concordância, e vários destes aspectos são colocados frequentemente em discussão.

Delimitando objetivos, portanto: (i) É possível analisar o mundo do trabalho apenas por sua correlação com o mundo do capital? (ii) As transformações que daí derivam produzem efeitos sociais? (iii) O Estado, como agente disciplinador, tem produzido um arcabouço que contemple adequadamente essa relação, à luz do cenário econômico globalizado?

\section{Atualidade e (a quarta) Revolução Industrial em andamento: produção, extração e trabalho no século XXI}

A evolução humana foi marcada por fatos amplamente documentados em abundante bibliografia, e sobre isto existe um reconhecimento consolidado. Abstraindo de fatos mais remotos, porém determinantes, como a escrita e subsequentemente o sistema métrico; a partir desses fatos o conhecimento humano evolui e chega ao final do século XVIII na Revolução Industrial, que foi, segundo Brynjolfsson e McAfee (2015, p. 6), "a soma de diversos avanços quase simultâneos na engenharia mecânica, química, metalurgia e outras disciplinas”, que resultou, àquela época, no motor a vapor.

Para Morris, citado por Brynjolfsson e McAfee (2015, p. 6) foi a maior e mais rápida transformação em toda a história do mundo, por sua capacidade de mudar a forma como o homem se relacionava com a produção e, por consequência, com o trabalho. Segundo os mesmos autores, "O progresso foi dolorosamente lento, quase invisível", todavia, nos últimos duzentos anos, aproximadamente, ocorreu algo classificado como "repentino e profundo", que produziu grande impacto, ou seja, o rápido desenvolvimento da tecnologia.

Morris citado por Brynjolfsson e McAfee (2015, p. 6) afirma que, "Embora a revolução [do vapor] tenha levado diversas décadas para ocorrer [...] foi, ainda assim, a maior e mais rápida transformação em toda a história do mundo". Assim, concluem os autores que a "Revolução Industrial trouxe consigo a primeira era das máquinas da humanidade - a primeira vez que o nosso progresso foi impulsionado, principalmente, pela inovação tecnológica”.

Desenvolvendo a mesma temática em uma ótica similar, Schwab (2018) amplifica esta abordagem do desenvolvimento tecnológico, fazendo uma referência a uma quarta Revolução Industrial. E como este engenheiro criador do Fórum Econômico Mundial (DAVOS - Suíça) chega até esta quarta ‘edição'? Segundo o autor, na primeira Revolução 
Industrial, ocorrida aproximadamente entre 1760 e 1840, com o advento do uso do vapor, o homem foi retirado da sua até então única opção de trabalho, que era a agricultura, e levado à indústria.

A segunda revolução, iniciada já em fins do século XIX entrando pelo século XX, foi baseada na introdução da energia elétrica, talvez a mais disruptiva das inovações humanas; e o conceito da produção em massa, que reformulou toda a vida em sociedade.

Seguiu-se a terceira revolução já na década de 1960, com a chegada do computador que teve por trás a revolução dos semicondutores -, e, na década de 1990, a internet - que criou o conceito das relações sociais e econômicas em rede. Neste ponto, Schwab (2018) enfatiza que, apesar de promover o rompimento de muitos paradigmas, em termos econômicos as alterações foram pequenas.

Considera ainda Schwab (2018) que o impacto desta quarta Revolução Industrial será muito mais abrangente, chegando a referir-se a ela como, talvez, uma nova Renascença, tamanho será o seu impacto em toda a vida da sociedade. Schwab (2018) considera que a abrangência, a velocidade e a amplitude dessa revolução estão ainda por serem compreendidas, e que esta revolução consegue fundir as tecnologias do mundo físico, digital e biológico, fazendo mais, em um processo simbiótico, construírem-se e amplificarem-se umas às outras. Define, assim, o que poderá ser identificado como um processo que tende a multiplicar o conhecimento de forma talvez, exponencial.

Imperioso apelar para o aspecto subjetivo da economia, no sentido de que esta, enquanto fluxo e fenômeno mais que presente na contemporaneidade, carrega consigo aspecto de auto aprendizado e construção. Destarte, seu epicentro sempre gravita em torno de elementos atinentes ao tempo de sua ocorrência, logo, a Revolução de ontem sempre terá sido em menor escala; enquanto a do amanhã, sempre arrebatadora em relação à anterior: um valor histórico que não abdica, mas se constrói de época em época.

Essa quarta Revolução Industrial, portanto, pode ser reconhecida como o somatório das possibilidades alcançadas por aquelas que a precederam, e tendo grande impacto sobre o mundo da produção, e como consequência lógica, sobre o mundo do trabalho, nas mudanças potenciais que poderá ocorrer nas relações do homem com este.

Schwab (2018) fala das possiblidades criadas por um ambiente aberto e que permite as necessárias interações que possibilitarão narrativas positivas, fazendo com que os frutos destas transformações sejam disponíveis a todos. Considera também que todas as mudanças que têm ocorrido "são fundamentais e difíceis de serem desfeitas" (SCHWAB, 2018, p. 21) e 


\section{Economia e (direito do) trabalho em um contexto de quarta revolução}

\section{industrial: uma análise crítica da lei 13.467/17.}

que a tecnologia não se constitui em uma força externa que não deve nos impor uma escolha eminentemente binária: "aceitar e viver com ela" ou "rejeitar e viver sem ela" (SCHWAB, 2018, p. 13).

As palavras do autor revelam uma perspectiva otimista quanto aos efeitos da aplicação da tecnologia, cada vez mais intensa e disseminada, especialmente sob a ótica da produtividade, a qual seria, segundo ele, um determinante fator de crescimento a longo prazo a proporcionar melhores padrões de vida à sociedade. Com efeito, Schwab (2018) vai direto ao ponto. Pelo seu entendimento, a alta taxa de produtividade, pela via da tecnologia, se manifesta por "seu possível impacto negativo, pelo menos no curto prazo, no mercado de trabalho" (SCHWAB, 2018, p. 41). A este respeito, oferece como exemplo a China, onde, nos últimos anos, a participação do trabalho - ou da mão de obra - como fração relativa do PIB, “sofreu um 'declínio significativo' (SCHWAB, 2018, p. 20).

Isto ocorreu pela redução dos custos dos "bens de investimento" (SCHWAB, 2018, p. 21), fruto das inovações ocorridas, o que leva inexoravelmente as decisões de investimentos a priorizarem o capital em detrimento do trabalho. Pondera ainda que os “impactos da tecnologia sobre os empregos não são novos" (SCHWAB, 2018, p. 41) e remontam à terceira década do século passado, quando já Keynes alertava sobre este fato e sua consequência, o desemprego, "pois nossa descoberta dos meios de economizar o uso do trabalho ultrapassa o ritmo no qual podemos encontrar novos usos para o trabalho" (SCHWAB, 2018, p. 41).

Logo, uma conta que não fecha, qual seja, a otimização atrelada à reciclagem dos postos de trabalho. Essa otimização se revela, por consequência lógica, do crescimento produtivo.

Já em princípios do mesmo século ou, antecedente à visão de Keynes, o homem já discutia os efeitos das relações de trabalho dentro das organizações, e Taylor (1987) registrava suas observações sobre as vantagens de sua abordagem científica, de que o homem comum era capaz de produzir de duas a quatro vezes mais coisas úteis para a sociedade, do que ocorria anteriormente. A este propósito ele argumenta que

Este aumento do esforço humano é naturalmente devido a muitas coisas, além da melhor habilidade pessoal do trabalhador. É devido à invenção do trem a vapor, à eletricidade, à utilização das máquinas, às invenções grandes e pequenas e aos progressos da ciência e da educação. (TAYLOR, 1987, p. 129). 
Relativamente aos avanços que ocorriam no modo de produzir e a perspectiva de que isto teria impacto sobre o emprego das pessoas, o mesmo Taylor (1987) pondera que

Aqueles que temem seja a maior produção de cada indivíduo capaz de arrastar muitos homens ao desemprego, devem compreender que nenhum elemento torna os países civilizados dos não civilizados, os povos prósperos dos povos pobres; nos primeiros os homens são, em média, 5 a 6 vezes mais produtivos que nos outros. (TAYLOR, p. 129)

Paralelamente aos apontamentos de Taylor nos Estados Unidos, Fayol (1994, p. 43), na Europa, compilava seus princípios e expressava suas ideias em torno do "corpo social", distinguindo assim as tarefas restritas às pessoas (ou aos trabalhadores), de tantas outras "funções que põem em jogo a matéria-prima e as máquinas". Ao enunciar seus princípios, tomou o cuidado de afastar qualquer significado de rigidez na sua aplicação, uma vez que seria "necessário ter em conta circunstâncias diversas e variáveis, homens igualmente variáveis e diferentes, e muitos outros elementos variáveis".

Nesta perspectiva Fayol (1994, p. 43) defendia estruturas que se revelassem "maleáveis e suscetíveis de adaptar-se a todas as necessidades". Estes conceitos de produtividade em Taylor, e de flexibilidade em Fayol, serão certamente retomados mais adiante nas discussões ao entorno dos problemas que hoje se manifestam na forma de desemprego e desigualdade.

Retomando a perspectiva de Schwab (2018, p. 42) acerca dos efeitos das mudanças produzidas pela tecnologia (coração da Quarta Revolução Industrial), a propósito do desemprego, admite existirem dois campos que se opõem, sendo o primeiro daqueles "que acreditam em um final feliz", ou seja, os deslocados encontrarão outros empregos; e em contrapartida "aqueles que acreditam que o fato levará a um progressivo Armagedon social".

Observa-se que o autor materializa sua ideia quanto ao desemprego, abrindo em seu texto um capítulo específico em que trata dos 'Impactos', e os subsequentes subtítulos 'Crescimento', 'Envelhecimento', 'Produtividade' e finalmente 'Emprego', com um acréscimo a este sobre a 'Substituição do trabalho'. Neste ponto, o autor pondera sobre os riscos ao emprego em uma economia como a dos Estados Unidos, onde segundo ele, citando pesquisa da Universidade de Oxford (FREY \& OSBORNE, 2013), 47\% dos empregos estariam submetidos a algum tipo de risco, estimando que isto poderia acontecer em uma ou duas décadas. 


\section{Economia e (direito do) trabalho em um contexto de quarta revolução}

\section{industrial: uma análise crítica da lei 13.467/17.}

Afirma ainda o mesmo Schwab (2018, p. 44), a propósito da mesma pesquisa, que tal fato poderá assumir escopo de determinada magnitude, que promoverá grandes alterações em um ritmo muito mais veloz "do que aquele ocorrido no mercado de trabalho pelas revoluções industriais anteriores". A este respeito, cita por exemplo, os 'Operadores de telemarketing' que se veem ameaçados pela inteligência artificial criada pela Apple (SIRI).

Desta maneira, o homem superou as duas primeiras revoluções industriais, no conceito de Schwab (2018), e chega à terceira, onde questões de ordem processual impõem novas soluções disruptivas; e à quarta, onde a tecnologia volta a impor novas questões ligadas ao trabalho, e as discussões começam a se acentuar.

Fato é que a nova realidade tecnológica que acomete a atualidade irá proporcionar uma percepção acerca da nova onda de revolução industrial em um modo nunca antes visto. Agora, a tecnologia não somente aperfeiçoa a operação, como também se vê em condições de substituir seu principal operador: o ser humano.

Na mesma medida em que postos de trabalho se vão, tantos outros surgem, contudo, retomando o marco teórico explorado, não na mesma velocidade surgem novos, como aquela em que se vão os antigos. Esse intervalo é de extensão imensurável, o que poderá acarretar toda uma nova conjuntura acerca de como a sociedade irá experimentar a quarta onda da Revolução da Indústria.

A este respeito a narrativa de Brynjolfsson e McAfee (2014) revela que ambos, ao estudar o impacto das tecnologias digitais sobre as atividades humanas, pensaram ter uma compreensão adequada do que estas tecnologias representavam em termos de suas capacidades e limitações. A surpresa é que ambos se viram diante de uma realidade tecnológica que assumia um espectro muito mais abrangente.

Daí, talvez, a preocupação de Schwab (2018) expressa anteriormente, sobre os efeitos da agora quarta Revolução Industrial, e sobre isto afirmando que

Estamos no início de uma revolução que alterará profundamente a maneira como vivemos e nos relacionamos. Em sua escala, escopo e complexidade, a quarta revolução industrial é algo que considero diferente de tudo aquilo que já foi experimentado pela humanidade. (SCHWAB, 2018, p. 11).

Bryjolfsson e McAfee (2014, p.10-11) afirmam que estamos vivendo um tempo que registra grandes avanços na tecnologia, particularmente na digital, e adicionam que "Estamos indo em direção a uma era que não será apenas diferente; será melhor, porque seremos 
capazes de aumentar tanto a variedade quanto volume de nosso consumo". Em que pese o otimismo quanto aos aspectos positivos, e estes são identificáveis, paradoxalmente completam mais adiante que "O progresso tecnológico deixará para trás algumas pessoas, talvez até muitas pessoas", o que pode conduzir a questionamentos quanto, no mínimo, ao aumento do volume de consumo, posto que, "deixando para trás algumas pessoas, talvez até muitas pessoas", não há como deixar de inferir livremente que isto produzirá impacto no mundo do trabalho, e como consequência, no consumo. Estes últimos, umbilicalmente ligados.

Um aspecto importante deste processo, já percebido nos dias atuais, e reconhecido por Schwab (2018), diz respeito ao fato de que $17 \%$ da população mundial não viveu sequer os efeitos benéficos da terceira Revolução Industrial. Segundo o autor, quase 1,3 bilhão de pessoas vivem em áreas sem acesso à internet, em parte também pela rápida difusão destas tecnologias, mas que ocorrem também de forma muito desigual, o que conduz a frações de populações a que ele se refere com recorrência como "excluídos digitais".

As considerações construídas até aqui visam esclarecer por um cenário onde a economia, o gerenciamento e o modo de extração ou produção se veem intimamente entrelaçadas para com o trabalho. Por conseguinte, o modo de se fazer ou conduzir a economia, sim, repercute igualmente no mercado de trabalho, incentivando então elemento nato de proteção deste último, qual seja, o direito do trabalho.

Constatação inicial necessária para então se avançar em como essa relação funciona exatamente, entre âmbito acadêmico e prático, o que será objeto das próximas colocações.

\section{Globalização e precariado}

A Revolução Industrial irrompe durante o século XVIII enquanto evento de caráter histórico o qual provocou profundas inflexões no paradigma social, agravando-se, século a século, conforme evoluíam os recursos e a tecnologia da indústria.

Tal qual se agravaram os meios de produção, atrelados à tecnologia cada vez mais de ponta, observou-se etapas da Revolução das Indústrias cada vez mais transformadoras, revelando por um entrelaçamento muito bem engendrado entre tecnologia, trabalho e consumo.

Emerge então o século XXI, contextualizado sob uma realidade de quarta Revolução Industrial, sob a qual se prevê um desenvolvimento nunca antes visto dos meios de produção (cada vez mais tecnológicos e modernos), surgindo daí novos trabalhos e, em contrapartida, 'órfãos da Revolução Industrial', ou seja, muitas pessoas as quais, por questões de condição 
econômica e social, não conseguirão acompanhar o ritmo dos novos tempos e, nem mesmo, perceber os benefícios de uma realidade de indústria globalizada e interligada.

Neste último sentido, conforme se confere do recorte anterior, comparativamente, cada Revolução Industrial de fato teve, em caráter global, uma taxa de população que não se viu minimamente amparada pelas abruptas mudanças ocasionadas pela (r)evolução e modernização do setor das indústrias, tornando trabalhadores obsoletos ou, como em um contexto atual, pessoas analógicas em um mundo digital.

A partir das considerações retro construídas, é necessário avaliar os efeitos das transformações que se manifestam no seio das relações capital/trabalho, desenvolvendo algumas visões que delas decorrem.

De modo concreto, na medida em que estas relações se desenvolvem, as ciências sociais, muito além das econômicas e das gerenciais, procuram lançar alguma luz e propor alguns caminhos na busca, em certa medida, de um equilíbrio; oferecendo às partes as condições que lhes permitam o progresso mútuo ou, nas palavras de Taylor (1987, p. 31), "assegurar o máximo de prosperidade ao patrão e, ao mesmo tempo, o máximo de prosperidade ao empregado"; ou, na perspectiva de Fayol (1994, p. 53), em que "A ideia de fazer os operários participarem dos lucros é muito sedutora. Parece que é daí que surgirá o acordo entre capital e trabalho".

Contudo, tais perspectivas não necessariamente se confirmaram no plano prático. Tomando inicialmente as palavras de Schwab (2018, p. 20), “A quarta revolução industrial irá gerar benefícios e, em igual medida, grandes desafios", admitindo que uma preocupação particular seja a desigualdade exacerbada, e que aqueles são difíceis de quantificar. Entre as razões apresentadas pelo autor, o resultado desta desigualdade é que seus grandes beneficiários são os provedores de capital intelectual ou físico - os inovadores, empreendedores, investidores.

$\mathrm{Na}$ perspectiva do mesmo autor, ocorrem dois efeitos destrutivos "que a tecnologia exerce sobre os empregos"; o primeiro faz a tecnologia substituir o trabalho pelo capital, enquanto o segundo é "a demanda por novos bens e serviços", o que faz aumentar ou leva "à criação de novas profissões, empresas e até mesmo indústrias". (SCHWAB, 2018, p. 42).

Mas como este desequilíbrio pode ser analisado em uma outra perspectiva? Standing (2013) abre seu texto afirmando que, nos anos 1970, o pensamento neoliberal era voltado ao princípio do crescimento e o desenvolvimento a partir dos mecanismos de mercado pela via de uma maior "concorrência e competitividade"; e um dos temas centrais era aumentar a 
flexibilidade do mercado de trabalho, com a consequente transferência dos "riscos e insegurança para os trabalhadores”. (STANDING, 2013, p. 15). Um dos temores àquela época era de que, "a menos que os sindicatos fossem "domados", a desindustrialização [...] se aceleraria, o desemprego aumentaria, o crescimento econômico seria mais lento". (STANDING, 2013, p. 21).

Este era o cenário, personalizado por figuras como Margaret Thatcher e Ronald Reagan, receptores das mensagens do pensamento à época neoliberal, que se reflete nos dias atuais, como argumento central para a reforma do direito do trabalho. (STANDING, 2013)

Também segundo Standing (2013, p. 22), "Na medida em que ocorria a globalização e os governos e corporações se perseguiam mutuamente para tornar suas relações trabalhistas mais flexíveis, o número de pessoas em trabalho inseguro aumentou”.

Notadamente acerca deste tema, Uriarte (2001) assevera que a globalização é a nova questão social do século XXI, desmantelando e ao mesmo reconstruindo os próprios conceitos de mercado e trabalho. Conforme sustenta o mesmo autor:

Além de seus diversos aspectos e manifestações - cuja variedade a converte em um fenômeno complexo, multifacetado e dinâmico -, a globalização pode ser reduzida, na sua mais íntima essência, na expansão e aprofundamento da economia capitalista e seus postulados teóricos, tais como livre competência, mercado, câmbio livre, incremento das exportações, etc., e no predomínio do capital financeiro.

$[\ldots]$

Ser local em um mundo globalizado é uma deficiência. A mobilidade do capital e meios de comunicação produziu uma compreensão do espaço e tempo em tal medida, que bem poderia se falar no fim da geografia com bastante mais propriedade, e muito menos frivolidade, que no pretenso fim da história. Hoje, no mundo globalizado, ou as elites são móveis e a comunicação instantânea, ou não são elites. Tudo isso resultou em uma tremenda vantagem ao capital sobre o Estado e sobre o trabalho, já que a mobilidade quase instantânea de que hoje disfruta o capital, contrasta com a necessária localização do Estado nacional e a localização cultural do fator trabalho, que por razões humanas, familiares e econômicas, é infinitamente mais sedentário e arraigado do que o capital. Assim, a globalização contribui para que o poder político seja cada vez menos autônomo e para que, em geral, os contrapesos nacionais percam parte de sua eficiência; entre eles, o direito do trabalho e a ação sindical.

Naturalmente, esse processo vai acompanhado de uma ideologia legitimadora, que tende a privilegiar o capital sobre o trabalho. A competitividade da empresa no 


\section{Economia e (direito do) trabalho em um contexto de quarta revolução}

\section{industrial: uma análise crítica da lei 13.467/17.}

mercado global se converte no bem supremo a que se subordinam os demais. (URIARTE, 2001, p. 3-4, tradução nossa).

Más allá de sus diversos aspectos y manifestaciones -cuya variedad la convierten en un fenómeno complejo, multifacético y dinámico-, la globalización puede ser reducida, en su más íntima esencia, a la expansión y profundización de la economía capitalista y de sus postulados teóricos, tales como libre competencia, mercado, libre cambio, incremento de exportaciones, etc., y al predominio del capital financiero. $[\ldots]$

Ser local en un mundo globalizado es una minusvalidez. La movilidad del capital y de las comunicaciones ha producido una compresión del espacio-tiempo en tal medida, que bien podría hablarse de un fin de la geografía con bastante más propiedad y menos frivolidad que del pretendido fin de la historia. Hoy, en el mundo globalizado, las elites son móviles y de comunicación instantánea, o no son elites. Y todo esto ha dado una ventaja tremenda al capital sobre el Estado y sobre el trabajo, ya que la movilidad casi instantánea de que hoy disfruta el capital, contrasta con la necesaria localización del Estado nacional y la cultural localización del factor trabajo, que por razones humanas, familiares y económicas, es infinitamente más sedentario y arraigado que el capital. Así, la globalización contribuye a que el poder político sea cada vez menos autónomo y que, en general, los contrapesos nacionales pierdan parte de su eficacia; entre ellos, el Derecho del trabajo y la acción sindical. Naturalmente, este proceso va acompañado de una ideología legitimadora, que tiende a privilegiar al capital sobre el trabajo. La competitividad de la empresa en el mercado global se convierte en el bien supremo al que se subordinan los demás. (URIARTE, 2001, p. 3-4).

Surge assim, conforme assegura Standing (2013, p. 23), a gênese de uma nova classe, o precariado. Estes não pertencem à classe dos trabalhadores, tampouco ao proletariado, o que foi definido pelo autor como um processo de "fragmentação das estruturas de classe nacionais", fruto da globalização; vivem também a perspectiva de privação de um emprego formal com perspectiva de longo prazo e horário definido e integral.

Classe proletariada, cuja assoladora realidade resultante da quarta Revolução Industrial convida para um novo contexto social do trabalhador. (ALVES, 2011; SCHWAB, 2016; STANDING, 2017). Sob esta perspectiva, será oportuno aprofundar acerca dos novos e reais desafios para a sociedade do século XXI, bem como quais seriam os reais objetivos da política, no que diz respeito à economia e direito do trabalho. Vale dizer, quais seriam as 
cabíveis manobras para, senão obstar os efeitos danosos que levariam à uma 'sociedade precariada', ao menos abrandá-los.

Um subproduto desta situação abordada por Standing (2013, p. 27) é o de que "A precariedade também implica a falta de uma identidade segura [ou identidade ocupacional], baseada no trabalho", agravada por situações em que pessoas com boa formação intelectual formal, aceitam empregos precários, abaixo de suas qualificações. Avalia também "que sempre há ambivalência e acordo implícito em relação a empenho, cooperação e aplicação de habilidades, bem como espaço para atos de sabotagem, furto e atividades inúteis".

Dado o estado de insegurança, mais ou menos generalizado, potencializado pelas circunstâncias nascidas com a crise de 2008, e abordado por Standing (2013), busca-se encontrar soluções que ofereçam um lenitivo às adversidades dessa nova classe nascente.

Em que pese a definição apresentar-se como um fato ligado aos países emergentes, em outras palavras ao Terceiro Mundo, este é um fenômeno globalizado e, segundo Standing (2013, p. 32), "o precariado está longe de ser [definido como] homogêneo", o que conduz a uma dificuldade para compreendê-lo e, eventualmente, apresentar soluções.

Enfim, deve ser levado a efeito alguma forma de dimensionar o precariado brasileiro, suas formas de relação com o trabalho e desigualdades derivadas da falta deste. Isto poderá dar embasamento a ações de longo prazo, oferecendo a possibilidade de um sentido de cidadania de forma mais ampla e perene.

Standing (2013, p. 268) oferece sua abordagem, segundo a qual a democracia deliberativa com a participação ativa dos cidadãos é um requisito básico. Complementa que esta não pode ocorrer a partir de "pessoas distraídas alimentadas com uma dieta de lugarescomuns e chavões, ela exige debate, contato visual, linguagem corporal, escuta e reflexão".

Este é o desafio.

\section{Economia, gerenciamento, produção e trabalho: uma análise crítica da Lei 13.467/17}

Em breve revisão, a economia evolui de forma contínua, no que diz respeito à Revolução Industrial, em especial aquela vivenciada na atualidade - a quarta. Adaptável e irrefreável, em uma nova realidade de tecnologia de ponta, muito mais articulada, polivalente e multifacetada, assim como meios de comunicação cada vez mais versáteis e velozes, a expectativa é de que os efeitos mais severos dessa nova (r)evolução ainda não tenham atingido seu ápice. 


\section{Economia e (direito do) trabalho em um contexto de quarta revolução}

\section{industrial: uma análise crítica da lei 13.467/17.}

Em todo caso, é previsível que suas resultantes trarão definitivas mudanças ao setor produtivo, sobretudo nos postos de trabalho, e à própria sociedade, em meio à qual já se vê despontar uma classe ainda não bem definida, que se denominaria precariado.

Vale dizer quanto a esse último, uma legião de pessoas, de trabalhadores, as quais não teriam mais lugar no mercado de trabalho, seja pela sua própria obsolescência, seja pela modernização intensiva, que eliminaria muitos postos de trabalho, não a tempo de surgirem outros novos.

Pondere-se que a quarta Revolução da Indústria não é fenômeno de materialização instantânea, é um fenômeno em movimento e em constante construção. Na visão de Bauman (2001), um processo fluido e cujos resultados práticos no cotidiano social somente poderão ser avaliados pelas gerações futuras.

Contudo, se utópica ou não, fato é que a realidade social, tal qual o início do século XXI a conheceu, irá mudar, drasticamente, em relativo curto prazo de tempo. Premissa a qual parte da evidente percepção de que os meios de produção, comunicação e forma de se fazer economia e política mudaram completamente, face às facilidades que surgiram na alvorada do século atual.

Essa disrupção provoca a inegável constatação de que todos os agentes sociais irão, de alguma forma, responder, reagindo conforme contexto global em que se encontrem.

Logo, a preliminar conclusão a que se chega é a de que a sociedade atual encontra-se no epicentro de uma (quarta) Revolução Industrial em curso. Ainda, Revolução que irá inflexionar meios de produção, economia, trabalho e consumo.

Este marco teórico, construído em etapas, revela uma correlação de intimidade entre a economia e trabalho: a primeira, praticada pelos meios e cadeia de produção, acaba por determinar a curva do pleno (des)emprego e, em contrapartida, o segundo, se revela como autêntico instrumento de controle e regulação do mercado em si.

Sem dúvida, portanto, um é dependente do outro, e ambos se correlacionam em práticas mercantis, muitas vezes, chanceladas ou obstadas pelo caráter jurídico do direito laboral, sempre com o objetivo de buscar uma realidade de mercado perfeita, visando orquestrar oferta, demanda e pleno emprego.

Conforme a escola Rüdiger,

De fato, a sociedade contemporânea sofre as mudanças acima descritas e propulsionadas pela globalização, a concentração dos capitais, a nova tecnologia, a universalização do mercado e as transformações no modo de gerenciar a empresa. A 
crise das grandes narrativas, isto é, da busca da emancipação, do justo, da verdade e do belo, está visível por toda parte, nesse mundo em transformação. O direito do trabalho não poderia permanecer ileso, pois é fruto dialético da correlação de forças econômicas, políticas e sociais. (RÜDIGER, 2004, p. 43).

Composto o cenário, é necessário, então, voltar a atenção para a recente alteração da legislação trabalhista, a reforma do trabalho. Transcrita pela Lei 13.467/17, é importante ao presente estudo abordar sobre qual a proposta de que se reveste essa manobra legislativa, e até onde ela encontra correspondência prática à luz dos novos e vindouros paradigmas sociais de que se trataram até aqui.

Em outras palavras, quer se esclarecer a quais objetivos se propõe a Lei 13.467/17. Para tanto, optou-se recorrer à fala de um dos maiores porta-vozes da reforma trabalhista nacional, José Pastore, em entrevista concedida ao jornalista Jacílio Saraiva:

Estudioso há mais de 50 anos das relações de trabalho, emprego e educação, o especialista acredita que, hoje, a insegurança jurídica domina a agenda dos empreendedores. "Eles estão sempre assustados com o que pode ocorrer na Justiça do Trabalho. Com regras mais claras, a tendência é de crescimento dos negócios", diz. Na entrevista a seguir, ele fala como a reforma pode aumentar o número de vagas nas companhias e quais os impactos esperados em setores como comércio e serviços.

$[\ldots]$

Valor: Como toda mudança estrutural, há vantagens e desvantagens?

Pastore: A reforma traz custos e oportunidades para as empresas em geral. Entre os custos, há o aumento das multas em caso de infração e o crescimento das despesas processuais. Isso vale também para as pequenas. Nas oportunidades, aparece a liberdade de negociar com os sindicatos e ter certeza de que o que for negociado vai valer mais do que a CLT. E, nessa negociação, empregados e empregadores poderão fazer ajustes nas jornadas, férias e outros direitos que hoje são rígidos. Uma grande abertura foi dada para negociar a produtividade, crucial para a competitividade dos negócios. Ela pode ser atrelada a bônus sobre os quais não incidem encargos. Para as pequenas, é de grande valor a criação de duas modalidades de tempo parcial [16 e 30 horas semanais], o contrato intermitente e de autônomos. São opções já usadas na informalidade que, agora, poderão ser aplicadas com segurança. A chegada da terceirização para atividades fim e meio constitui ainda uma excelente oportunidade para ampliar os negócios. (PASTORE, 2017). 


\title{
Economia e (direito do) trabalho em um contexto de quarta revolução
}

\section{industrial: uma análise crítica da lei 13.467/17.}

É possível, então, se dizer que o argumento adotado pelos corpos políticos e agentes econômicos foi justamente aquele de que o direito do trabalho promove uma proteção social exacerbada e exagerada. Seria um direito retrógado, completamente desconexo com os atuais desafios econômicos nacionais, logo, não mais um agente de proteção, mas de custo para o setor produtivo, diga-se, um dos mais sintomáticos a dificultar o crescimento da economia nacional, o que acabaria por, ironicamente, incrementar a taxa de desemprego.

Seria, então, o direito do trabalho vilão de si mesmo? No viés desta temática, a Lei 13.467/17 revela uma proposta eminentemente voltada para o plano econômico, enquanto instrumento de articulação para promoção de empregos e aumento do aproveitamento pelo setor produtivo.

Para tanto, o direito do trabalho foi reformulado enquanto norma de menor poder cogente, voltado para possibilidade de negociação. Em suma, teve seu viés protetivo sintomaticamente diminuído, na promessa pela diminuição do custo do contrato de trabalho, abrindo portas para que a iniciativa privada consiga conduzir suas práticas de forma menos onerosa e, como consequência, gerar mais empregos.

Contudo, conforme muito bem esclarece Supiot (2013),

\begin{abstract}
Em contraposição ao que diz o dogma dos desregulamentadores do mercado de trabalho, os índices de desemprego em qualquer país dependem muito mais da organização do comércio internacional e do direito societário do que da legislação trabalhista local. A ideia de que uma reforma do direito trabalhista criará postos de trabalhos é uma ilusão: a completa revogação de toda norma reguladora do trabalho assalariado apenas teria impacto sobre o desemprego. SUPIOT, 2013, p. 160).
\end{abstract}

Observa-se então que a reforma advinda da Lei 13.467/17 parte de uma secular demagogia. Ainda de acordo com Supiot,

Estas políticas decorrem da (falsa) suposição de que a legislação trabalhista constitui o principal obstáculo ao pleno emprego e deveria ser desmantelada para aumentar a competitividade das empresas e,

$[\ldots]$

o denominador comum tem sido a ideia de que determinadas garantias estabelecidas (jornada integral de trabalho, salários compatíveis, proteção contra demissão) são os responsáveis pelas dificuldades que experimentam certos setores da força de trabalho para encontrar emprego. Dado o maior ou menor ânimo do "mercado social" da época, isto tem significado de fato uma redução destas garantias, ou então 
a transferência de parte de seus custos ao Estado ou a Seguridade Social. (SUPIOT, 2013, p. 157-158).

Daí, se justifica toda a construção teórica que precede o presente capítulo. O cenário econômico não pode vir resumido por um único fator, assim como sua proporção se projeta no tempo, operando diferentes efeitos conforme época e contexto econômico de cada país.

É um discurso de interconexão, que visa tornar compreensível que uma economia dinâmica está atrelada a um processo de produção dinâmico, também imerso em uma sociedade igualmente dinâmica. $\mathrm{O}$ vetor desse dinamismo, dentre várias narrativas das quais se poderia citar, resulta na quarta Revolução Industrial em curso, a qual foi concebida em bases muito mais profundas do que o simples contrato de trabalho, como o conhecíamos até então.

Portanto, desenvolvimento econômico, atrelado a novos empregos, não se faz com a redução de proteção social. Diga-se, proteção essa que é o propósito fulcral do direito do trabalho.

Nas palavras de Ramalho,

ao direito do trabalho subjaz, como é tradicionalmente reconhecido, um princípio geral de protecção, mas cremos que esse desígnio protectivo não se desenvolve apenas em favor do trabalhador subordinado e com o objetivo de compensar a sua inferioridade negocial, conforme entendem os subscritores da autonomia dogmática do direito laboral na construção tradicional do problema, mas se desenvolve também em benefício do empregador, com o objectivo de garantir o cumprimento dos deveres especialmente amplos que the incumbem no contrato de trabalho e, mediatamente, para viabilizar o próprio contrato. Por este motivo designamos este princípio como um princípio geral de compensação e lhe reconhecemos duas vertentes: uma vertente de protecção ou de salvaguarda dos interesses do trabalhador e uma vertente de salvaguarda dos interesses do empregador. (RAMALHO, 2010, p. 976).

Também é importante indicar o quão superficial foi a visão do legislador, ao ter na desconstrução das bases trabalhistas a solução formal para a economia nacional.

Muito ao contrário, face às adversidades de uma sociedade precariada, a iniciativa legislativa de promoção irrestrita da economia não encontra espaço para guarnecer o Brasil de condições mínimas no enfrentamento aos novos desafios da quarta Revolução Industrial. 


\section{Economia e (direito do) trabalho em um contexto de quarta revolução}

\section{industrial: uma análise crítica da lei 13.467/17.}

Não se confere, assim, uma política de estratégia legislativa a qual se adeque às necessidades mais imediatas para uma economia de resistência e um aparato social minimamente protegido.

Isto posto, a quarta Revolução Industrial demanda por iniciativas políticas que alcancem êxito em efetivar medidas globalizadas, enxergando o cenário econômico atrelado a outras narrativas, como, por exemplo, o próprio trabalho.

Não vale sacrificar um, para beneficiar o outro, pois, repita-se, é tudo uma coisa só. Portanto, em uma realidade econômica inovadora, com o potencial de incrementar ainda mais o índice de desemprego, valeria, então, defender um raciocínio inverso. Ou seja, outorgar proteção laboral, de modo a promover a economia, já que o raciocínio inverso, conforme prova a história, não traz outra consequência senão a própria precariedade, conforme Standing (2017).

\section{Conclusões}

O mundo está em constante mudança, nos mais diversos fluxos que a existência humana. Da política à religião, da cultura ao modo de produção, da filosofia ao direito, é fato que a sociedade em seu todo, desde tempos, não vai mais percebida enquanto fator estático, unívoco, mas sim, de elementos multifacetados, altamente adaptáveis, cujas narrativas estão em constante evolução.

Dentre os mais diversos elementos de constituição social, entenda-se, ciências ou linhas de estudo que centram os mais diversos assuntos do dia a dia social, o presente recorte procurou individualizar a economia, o gerenciamento, o modo de extração ou produção, e o trabalho enquanto expressões de existência, senão coligadas, diretamente influentes umas das outras.

Quanto aos primeiros elementos partiu-se então da contextualização histórica e evolutiva da Revolução Industrial, a qual mesmo após três grandes narrativas encontrou o caminho para, em pleno século XXI (ou ainda antes), dar início a uma quarta versão.

Como não poderia ser diferente, esta versão comunga o aparato geral da realidade contemporânea, ou seja, une fatores como globalização, (r)evolução tecnológica, facilidade de comunicação, e dinamismo inventivo, para criar as bases de um futuro paradoxal.

Paradoxal, pois ao mesmo tempo em que é notável sob o aspecto industrial, incluindo o discurso acerca das possibilidades humanas para a produção, ao mesmo tempo, preocupante, 
na medida em que a rápida reinvenção do gerenciamento, bem como do modo de extração ou produção, resultará na eliminação de vários postos de trabalho.

Postos, os quais sim, eventualmente ressurgirão sob novas vestes, contudo, não rápido o bastante para que toda essa gama de trabalhadores ditos por obsoletos encontre um novo posto dentro do mercado.

Conclui-se, então, pelo surgimento do precariado, o qual consiste justamente nessa casta que não conseguirá uma adaptação imediata dentro da nova realidade do ambiente laboral.

Inobstante ser uma realidade previsível, é também impossível prever quando ou exatamente quem irá sofrer com essa alteração de paradigma. Sem embargo, ocorrerá em escala global, com uma profunda alteração em nível macro da economia, o que incentiva alguns questionamentos.

Paralelamente a isso, implanta-se no Brasil uma nova roupagem ao direito do trabalho. A proposta de uma espécie de flexibilização, a qual visa promover o crescimento econômico por meio de um direito negociado, reduzindo seu aspecto protetivo e, em franco e aberto discurso, propiciando ao setor produtivo meios lícitos para maior obtenção de lucro.

Valeria então dizer que, reduzindo o caráter protetivo do direito do trabalho e, portanto, os custos do contrato de trabalho, ocorreria o natural aquecimento do setor econômico, gerando, como via de consequência, mais empregos.

O problema é que tal raciocínio parte de uma premissa já ultrapassada, ou seja, aquela de que o direito do trabalho caminha em paralelo à economia, quando, muito ao contrário, desde sempre andaram históricamente juntos.

A concepção da Lei 13.467/17 baseou-se no pressuposto de que o aspecto protetivo do direito obreiro acarretava demasiados custos ao setor produtivo, colocando em dúvida sua própria essência e imprescindibilidade.

Seria a chave então, para uma sociedade próspera e de maiores recursos, a roupagem de um direito obreiro eminentemente negocial.

Portanto, alinhavando ambos os discursos, constata-se que, dado o cenário de (r)evolução de mercado e indústria, condenar a construção social equivale a um suicídio de ordem política.

A Lei 13.467/17, ao implementar uma repaginação no setor produtivo, ao revés de promover, muito ao contrário, condena o trabalho e a economia. Isto, pois conforme comprova a história, o mero surgimento de postos de trabalho advindos de um aquecimento 


\section{Economia e (direito do) trabalho em um contexto de quarta revolução}

\section{industrial: uma análise crítica da lei 13.467/17.}

inicial da indústria, não se sustenta a longo prazo pois, ao final das contas, o que fortifica a empresa é o cenário econômico mundial, bem como a atuação do Estado em consonância com este. A compreensão desta simbiose foi a busca deste texto.

Não é um único fator necessário para a promoção da economia, logo, ao aferir o trabalho como vilão, a um só tempo, promete-se o que não será cumprido, bem como desconstrói-se todo um veio de proteção social.

Ainda com maior efeito, postos de trabalho esses os quais, inexoravelmente, tenderão a sumir dentro dos próximos anos, expondo a sociedade a um cenário de demissão em massa, desamparado de indústria e economia sólidas ou elementos de proteção objetiva ao trabalhador.

Assim, questiona-se, o Brasil está pronto para a quarta Revolução Industrial? Ao que parece, não.

\section{Referências}

ALVES, Giovanni. Trabalho e subjetividade: o espírito do toyotismo na era do capitalismo. São Paulo: Boitempo, 2011. 164 p.

BAUMAN, Zygmunt. Modernidade líquida. Rio de Janeiro: Zahar, 2001.

BRYNJOLFSSON, Erik; MCAFEE, Andrew. A segunda era das máquinas: trabalho, progresso e prosperidade em uma época de tecnologias brilhantes. Rio de Janeiro: Alta Books, 2015. $352 \mathrm{p}$.

FAYOL, Henri. Administração industrial e geral: previsão, organização, comando, coordenação, controle. São Paulo: Atlas, 1990. 138 p.

HOBSBAWN, Eric. Era dos extremos: o breve século XX - 1914-1991. São Paulo: Companhia das Letras, 2002. 598 p.

MAIA, Adinoel Motta. A era Ford: Filosofia, ciência, técnica. Salvador: Casa da Qualidade, 2002. 144 p.

OHNO, Taiichi. O Sistema Toyota de Produção: além da produção em larga escala. Porto Alegre: Bookman, 1997. 149 p.

PASTORE, José. Reforma beneficia os pequenos. [Entrevista concedida a] Jacílio Saraiva. Valor Econômico, São Paulo, Caderno Especial, p. F3, 29 set. 2017.

RAMALHO, Maria do Rosário Palma. Da autonomia dogmática do direito do trabalho. Coimbra: Livraria Almedina, 2000. 1144 p. 
RÜDIGER, Dorothee Susanne. Teoria da flexibilização do direito do trabalho: uma tentativa de contextualização histórica. Prima Facie, João Pessoa, v. 3, n. 4, jan./jun. 2004. Disponível em: <http://www.periodicos.ufpb.br/ojs/index.php/primafacie/article

/view/4455>. Acesso em: 14 abr. 2018.

RYDLEWSKI, Carlos. O destino do trabalho. Valor Econômico, São Paulo, 12 jan. 2018. Caderno Eu e Fim de Semana, p. 10-17.

SCHWAB, Klaus. A quarta revolução industrial. São Paulo: Edipro, 2016. 159 p.

SHIMOKAWA, Koichi; FUJIMOTO, Takahiro. O nascimento do lean. Porto Alegre: Bookman, 2011. 296 p.

SILVEIRA JÚNIOR, Luís Carlos. A nova revolução industrial. Porto Alegre: Sagra DC Luzzatto, 1993. $126 \mathrm{p}$.

SLOAN, Alfred P. Meus anos com a General Motors. São Paulo: Negócio Editora, 2001. $408 \mathrm{p}$.

STANDING, Guy. O precariado: a nova classe perigosa. Belo Horizonte: Autêntica Editora, 2017. 285 p.

SUPIOT, Alain. Lei e trabalho. Um mercado mundial de regras? Tempos Históricos, Marechal Cândido Rondon, v. 17, $1^{\circ}$ semestre 2013, p. 157-169. Disponível em: <http://erevista.unioeste.br/index.php/temposhistoricos/article/view/9013/6604>. Acesso em: 14 abr. 2018.

TAYLOR, Frederick Winslow. Princípios de administração científica. São Paulo: Atlas, 1987. $242 \mathrm{p}$.

TETT, Gillian. Algoritmos e desigualdade. Valor Econômico, São Paulo, 23 fev. 2018. Caderno Eu e Fim de Semana, p. 22-23.

URIARTE, Oscar Ermida: Derechos laborales y comercio internacional. 2001. Disponível em: <https://wilfredosanguineti.files.wordpress.com/2011/06/derechos-laborales-y-comerciointernaconal-oscar-ermida.pdf $>$. Acesso em: 14 abr. 2018. 